\title{
DIAGNOSIS OF PARATUBERCULOSIS IN CATTLE: MICROBIOLOGICAL CULTURE, SEROLOGY AND PCR
}

\author{
Isabel A. Carvalho ${ }^{1}$; Vinicius E. B. Campos ${ }^{1}$; Iana M. Souza ${ }^{1}$; Larissa G. Zanardo ${ }^{1}$; Jose D. Ribeiro Filho ${ }^{1}$; Marcos J. P. \\ Gomes $^{2}$; Maria A. S. Moreira ${ }^{1^{*}}$
}

${ }^{1}$ Departamento de Veterinária, Universidade Federal de Viçosa, Viçosa, MG, Brasil; ${ }^{2}$ Faculdade de Veterinária, Universidade Federal do Rio Grande do Sul, Porto Alegre, RS, Brasil.

Submitted: April 19, 2011; Returned to authors for corrections: July 31, 2011; Approved: June 07, 2012.

\begin{abstract}
The aim of this study was to confirm clinical diagnosis of paratuberculosis in two cows showing suggestive clinical signs of the disease. Based on clinical signs, in culture and in IS900 PCR results from the individual milk samples it was possible to diagnose paratuberculosis in the cows studied.
\end{abstract}

Key words: Mycobacterium avium subspecies paratuberculosis (MAP); milk; cattle; IS900; ISMav2

Paratuberculosis, a chronic non-treatable enteritis of ruminants caused by Mycobacterium avium subspecies paratuberculosis (MAP), causes economic loss to dairy farmers worldwide and is characterized by an incubation period of several months. Infection generally occurs through the consumption of feed, water or colostrum contaminated with MAP (21). Clinical signs are progressive weight loss, decrease in milk production, low reproductive performance, low meat quality, early culling, chronic profuse diarrhea, cachexia, weakness, and can result in the death of the animal (3).

The importance of paratuberculosis is not only due by farm-level and industry-level economics. MAP might also play a role in Crohn's disease. This theory is based on the similar clinical signs and similar pathology to paratuberculosis and in detection of MAP from blood, breast milk and peripheral blood mononuclear cells (PBMC) from Crohn's disease patients. An earlier review (10) concluded that "the association of MAP and
Crohn's disease is no longer in question. However its role in causation of Crohn's disease remains to be defined". The most probable transmission route of MAP from animals to humans is milk and milk products. The presence of MAP in raw milk is compounded by the fact that there is evidence that the organism can survive the milk pasteurization process under certain conditions $(2,7,12)$.

Unfortunately, culture methods require six months to confirm that a sample is negative for MAP, besides requiring the addition of mycobactin $J$. Efforts have been made in the past few decades to develop protocols for the detection of MAP in feces, milk, tissue, food and environmental samples using several methods. Serology and fecal culture, however, are the most commonly used tests (17). Progress has recently been made to improve the sensitivity of PCR tests for MAP in milk.

The aim of this study was to confirm the clinical diagnosis of paratuberculosis in two cows with suggestive signs of the

\footnotetext{
*Corresponding Author. Mailing address: Departamento de Veterinária, Universidade Federal de Viçosa, Viçosa, Minas Gerais, 36570-000, Brazil.; Tel.: +55 3138991470 Fax: +55 313899 1457.; E-mail: masm@ufv.br
} 
disease using microbiological culture, serology and PCR.

Two cows showing suggestive clinical signs of paratuberculosis were attended at the Veterinary Hospital of Department of Veterinary (HOV/DVT) of the Federal University of Viçosa, Brazil (UFV) in 2007. The animals were approximately five (animal 1) and six (animal 2) years old and came from different dairy farms in the microregion of Viçosa, MG. On clinical examination the following signs were detected: severe diarrhea, weight loss and decreasing milk production and feeding.

From each animal, we collected fecal samples from rectum, approximately $10 \mathrm{~mL}$ of milk from each teat in a total of $40 \mathrm{~mL}$ and $3 \mathrm{~mL}$ of blood samples. From each milk sample collected, a $1 \mathrm{~mL}$ aliquot was separated for serologic testing. All samples were refrigerated until arrival at the Laboratory of Bacterial Diseases/DVT/UFV and kept refrigerated at $8{ }^{\circ} \mathrm{C}$. Feces and milk samples were processed within 24 hours after their arrivals at the laboratory. Blood samples were centrifuged at $500 \times g$ for 5 minutes, and serum samples were sent to the Laboratory of Veterinary Bacteriology (LABACVET), Federal University of Rio Grande do Sul (UFRGS), where an in house serum ELISA was performed. As a positive control we used one wild strain, courtesy of LABACVET/UFRGS. Feces samples were processed for MAP culture according to Stabel (19) and milk samples according to Pillai and Jarayao (13). One aliquot of milk samples were processed for DNA extraction and PCR and another for MAP cultivation.

After decontamination with $0.9 \%$ HPC overnight, feces and milk samples were inoculated into tubes containing Herrold's egg yolk medium (HEYM), two with mycobactin $J$ (Allied Monitor, Inc., Fayette, MO, USA) and two without. They were incubated at $37{ }^{\circ} \mathrm{C}$ for 18 weeks (9) and growth observations were made weekly. For sterility control, tubes containing HEYM without inoculums also were incubated at $37{ }^{\circ} \mathrm{C}$. Smears were prepared from feces samples after processing and from colonies observed and stained by ZiehlNeelsen (ZN) using a set for ZN staining (Newprov, Pinhais,
PR, Brazil) according to manufacturer's instructions.

To obtain a positive control sample of milk, a loopful of MAP positive control was inoculated in $50 \mathrm{~mL}$ of milk powder Molico® (Nestlé, São Paulo, Brazil) reconstituted with distilled water and autoclaved, according to the manufacturers' instructions. This positive control was subjected to the same processing as milk samples. A negative control sample was also obtained by repeating the same procedure, but without the addition of MAP. For the extraction of MAP DNA we used a Wizard ${ }^{\circledR}$ Genomic DNA Purification Kit (Promega, Madison, WI, USA) according to the protocol recommended by the manufacturer, and extracted DNA was stored at $8{ }^{\circ} \mathrm{C}$ for later use. To perform PCR tests we used the Go Taq ${ }^{\circledR}$ Green Master Mix (Promega). We performed PCR tests using two sets of primers: 5'-BN1 GTT ATT AAC GAC GCC CAG C-3 'and 5'BN2 GCA CTG TGT TGG ATG GCG TTA G-3', based on the insertion sequence IS900 (15) and F 5'-GTG AGT TGT CAT CCG CAG AT-3'e B2 5'-GCA TCA AAG AGC ACC GCT AC-3', based on the insertion sequence ISMav2 (14). PCRs were performed according to the authors' recommendations. Amplified fragments were visualized by electrophoresis on a 1 $\%$ agarose gel (Invitrogen, Washington DC, USA) in Trisborate-EDTA (TBE) stained with ethidium bromide $(1 \mathrm{mg} / \mathrm{mL})$ (Sigma-Aldrich, St Louis, MO, USA) using a UV transilluminator Eagle Eye II (Stratagene, La Jolla, CA, USA). Ultrapure water and LABACVET/UFRGS strain were used as negative and positive controls, respectively, and phage $\varphi \mathrm{X} 174 /$ HaeIII (Promega) as a molecular marker.

In house serum ELISA was performed on LABACVET/UFRGS (6), and milk ELISA was performed using Pourquier ELISA Paratuberculosis Antibodies Screening (Institut Pourquier, Montpellier, France). Plates were read at $\mathrm{OD}_{450 \mathrm{~nm}}$ using an ELISA reader and results were based on the optical densities of controls. Milk ELISA and plate reading were performed according to the manufacturers' instructions. The tests were performed in triplicate, and for each sample an average value from the three reactions was taken. 
After 18 weeks of incubation, colonies were observed in tubes with mycobactin $J$ from milk sample from animal 1 and it was not possible see colonies typical of MAP due to contamination in the tubes inoculated with fecal samples from both animals. Smears were made from both samples and stained with ZN. Clusters of bacilli alcohol acid-resistant were observed under microscope. There was no growth of colonies in tubes containing mycobactin $J$ from the milk samples from animal 2.
Serum sample from animal 1 was considered suspected and milk sample was considered negative when tested for ELISA. Samples from animal 2 were negative for both tests.

Amplified fragments (626 bp) of milk samples from animals 1 and 2 were observed using primers based on the insertion sequence IS900 (Figure 1A). Using primers based on insertion sequence ISMav2 there was an amplification (484 bp) only in the sample from animal 1 (Figure 1B).
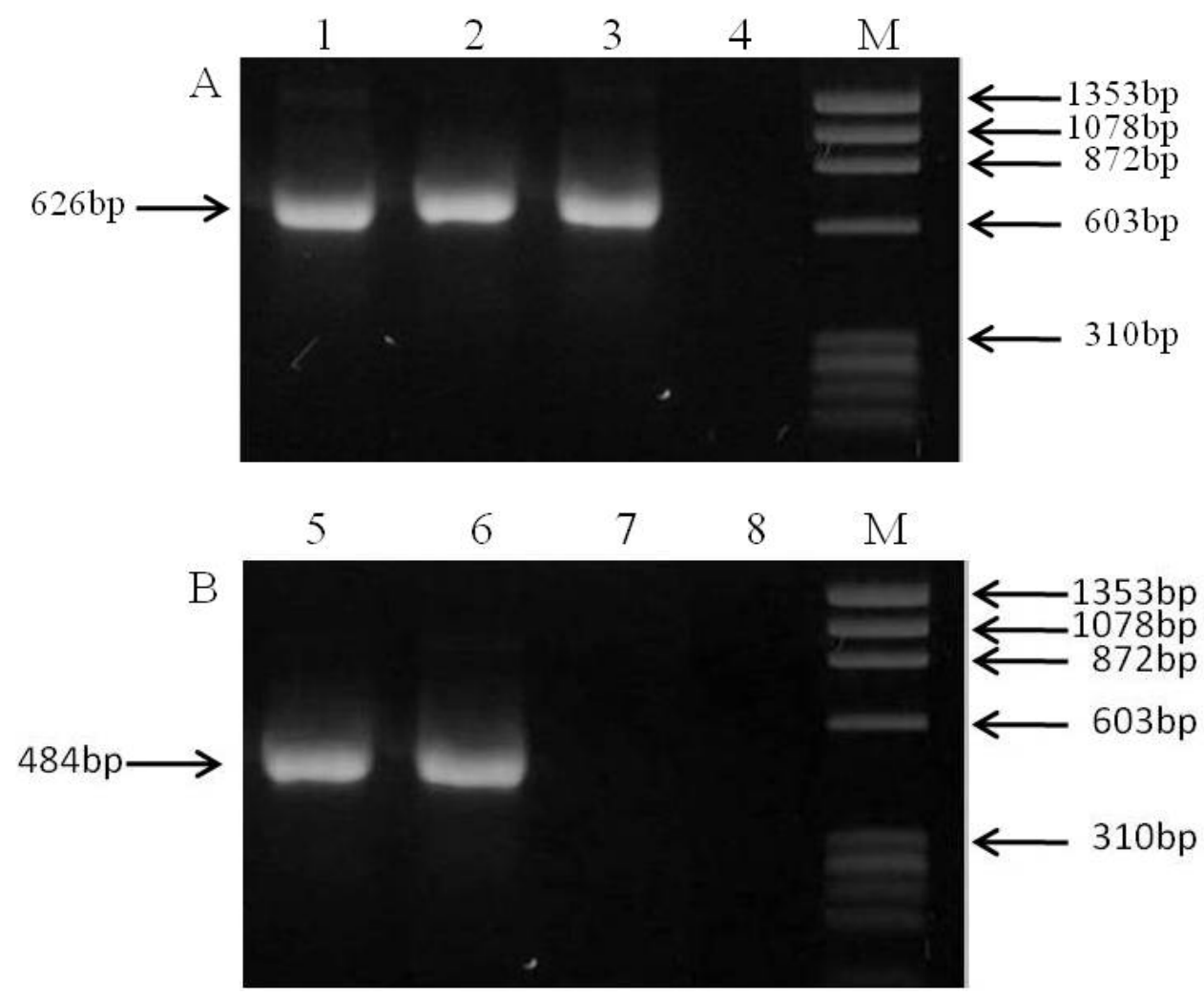

Figure 1. PCR products visualized in a $1 \%$ agarose gel using primers IS900BN1/IS900BN2 (A) and ISMav2F/ISMav2B2 (B). Lanes 1 and 5: positive control, K10 strain. Lanes 2 and 6: animal 1. Lanes 3 and 7: animal 2. Lanes 4 and 8: negative control (ultrapure water). M: molecular marker ( $\varphi$ X174/HaeIII).

Although fecal culture is the gold standard for MAP identification (3), we were unable to check results using this procedure because of the contamination found in tubes. Feces are naturally contaminated samples, and the long incubation time might have contributed to the failure of this procedure.
Contamination problems are frequent in fecal cultures (18). Colonies from milk samples of animal 1 were observed in the tubes containing mycobactin $J$ and they were white, convex, smooth and 4-5 $\mathrm{mm}$ in diameter. In an earlier study, (4) researchers observed colonies of MAP with the same 
characteristics, but of smaller size, 1-2 $\mathrm{mm}$ in diameter. We were unable to verify the presence of MAP in the tubes containing milk samples from animal 2 because of the presence of contaminants. MAP genome contains unique insertion sequences: IS900 (8) and ISMav2 (20). It has been reported that the copy number of IS900 is $14-18$, whereas there are approximately three copies of $\operatorname{ISMav2}$ in MAP $(1,20)$. We found amplified fragments in both milk samples using primers derived from IS900, but only in animal 1 using primers based on ISMav2. Although PCR based on IS900 is widely used for paratuberculosis diagnostics, this sequence could detect another Mycobacterium spp. (5). Therefore, we used ISMav2, another genetic element, more specifically. Amplified fragments in this study were cloned, sequenced and compared with existing sequences in GenBank and showed $99 \%$ homology (data not shown).

ELISA can detect specific antibodies in blood or milk with a high sensitivity, and antibodies generally develop late in the infection (16). In the present study, we found that neither of the two animals was MAP reagent using both serum ELISA and milk ELISA, although by the first test animal 1 was suspected. We did not expect the negative results in the ELISA tests because animals showed clinical signs of disease, meaning they were probably in the late stage of disease. Several factors might have played a role, such as the different sensitivities of tests, stage of lactation and the number of days after parturition samples were taken (22). Such information, however, was not presented in the clinical records of the studied animals. Earlier study (11) demonstrated that at the beginning of lactation the probability of being positive was highest in milk ELISA, whereas in serum ELISA this probability was highest at the end of lactation. Positive results in serum samples were expected because antibodies appear in serum before being detected in milk (11).

Based on the clinical signs of the animals and on the culture and PCR results from the individual milk samples it was possible to diagnose paratuberculosis in the cows studied.

\section{ACKNOWLEDGEMENTS}

The authors would like to thank FAPEMIG for financing this study and CNPq and CAPES for financing doctorate fellowship.

\section{REFERENCES}

1. Bull, T.J.; Hermon-Taylor, J.; Pavlik, I. et al. (2000). Characterization of IS900 loci in Mycobacterium avium subsp. paratuberculosis and development of multiplex PCR typing. Microbiol. 146 (9), 2185-2197.

2. Carvalho, I.A.; Silva, A.Jr.; Campos, V.E.; Moreira, M.A. (2009). Short communication: detection of Mycobacterium avium subspecies paratuberculosis by polymerase chain reaction in bovine milk in Brazil. J. Dairy Sci. 92 (11), 5408-5410.

3. Chiodini, R.J.; Van Kruiningen, H.J.; Merkal, R.S. (1984). Ruminant paratuberculosis (Johne's disease): the current status and future prospects. Cornell Vet. 74 (3), 218-262.

4. Collins, M.T. (2003). Update on paratuberculosis: I. Epidemiology of Johne's disease and the biology of Mycobacterium paratuberculosis. Ir. Vet. J. 56 (11), 565-574.

5. Cousins, D.V.; Whittington, R.; Marsh, I. et al. (1999). Mycobacteria distinct from Mycobacterium avium subsp. paratuberculosis isolated from the faeces of ruminants possess IS900-like sequences detectable IS900 polymerase chain reaction: implications for diagnosis. Mol. Cell. Probes. 13 (6), 431-442.

6. Gomes, M.J.P.; Driemeier, D.; Ribeiro, V.R. et al. (2002). Doença de Johne: isolamento do Mycobacterium avium subsp. paratuberculosis (Map) em um rebanho leiteiro infectado na região sul do Brasil. Acta Sci. Vet. 30 113-118.

7. Grant, I.R.; Williams, A.G.; Rowe, M.T.; Muir, D.D. (2005). Efficacy of various pasteurization time-temperature conditions in combination with homogenization on inactivation of Mycobacterium avium subsp. paratuberculosis in milk. Appl. Environ. Microbiol. 71 (6), 2853-2861.

8. Green, E.P.; Tizard, M.L.; Moss, M.T. et al. (1989). Sequence and characteristics of IS900, an insertion element identified in a human Crohn's disease isolate of Mycobacterium paratuberculosis. Nucleic Acids Research. 17 (22), 9063-9073.

9. Kalis, C.H.; Hesselink, J.W.; Russchen, E.W. et al. (1999). Factors influencing the isolation of Mycobacterium avium subsp. paratuberculosis from bovine fecal samples. J.Vet. Diagn. Invest. 11 (4), 345-351.

10. Nacy, C.; Buckley, M. (2008). Mycobacterium avium paratuberculosis: infrequent human pathogen or public health threat? American Society for Microbiology. 
11. Nielsen, S.S.; Grohn, Y.T.; Enevoldsen, C. (2002)., Variation of the milk antibody response to paratuberculosis in naturally infected dairy cows. $J$. Dairy Sci. 85 (11), 2795-2802.

12. Paolicchi, F.; Cirone, K.; Morsella, C. et al. (2005). Isolation of Mycobacterium avium subsp. paratuberculosis from commercial pasteurized milk. Proceedings of the 8th International Colloquium on Paratuberculosis, Copenhaguen, Denmark.

13. Pillai, S.R.; Jayarao, B.M. (2002). Application of IS900 PCR for detection of Mycobacterium avium subsp. paratuberculosis directly from raw milk. J. Dairy Sci. 85 (5), 1052-1057.

14. Shin, S.J.; Chang, Y.F.; Huang, C. et al. (2004). Development of a polymerase chain reaction test to confirm Mycobacterium avium subsp. paratuberculosis in culture. J. Vet. Diagn. Invest. 16 (2), 116-120.

15. Sivakumar, P.; Tripathi, B.N.; Singh, N. (2005). Detection of Mycobacterium avium subsp. paratuberculosis in intestinal and lymph node tissues of water buffaloes (Bubalus bubalis) by PCR and bacterial culture. Vet. Microbiol. 108 (3-4), 263-270.

16. Sockett, D.C.; Conrad, T.A.; Thomas, C.B.; Collins, M.T. (1992). Evaluation of four serological tests for bovine paratuberculosis. J. Clin. Microbiol. 30 (5), 1134-1139.

17. Sohal, J.S.; Singh, S.V.; Subhodh, S. et al. (2007). Mycobacterium avium subspecies paratuberculosis diagnosis and strain typing--present status and future developments. Indian J. Exp. Biol. 45 (10), 843-52.

18. Soumya, M.P.; Pillai, R.M.; Antony, P.X. et al. (2009). Comparison of faecal culture and IS900 PCR assay for the detection of Mycobacterium avium subsp. paratuberculosis in bovine faecal samples. Vet. Res. Commun. 33 (7), 781-791.

19. Stabel, J.R. (1997). An improved method for cultivation of Mycobacterium paratuberculosis from bovine fecal samples and comparison to three other methods. J. Vet. Diagn. Invest. 9 (4), 375-380.

20. Strommenger, B.; Stevenson, K.; Gerlach, G.F. (2001). Isolation and diagnostic potential of ISMav2, a novel insertion sequence-like element from Mycobacterium avium subspecies paratuberculosis. FEMS Microbiol. Lett. 196 (1), 31-37.

21. Sweeney, R.W. (1996). Transmission of paratuberculosis. Vet. Clin. North Am. Food Anim. Pract. 12 (2), 305-312.

22. van Weering, H.; van Schaik, G.; van der Meulen, A. et al. (2007). Diagnostic performance of the Pourquier ELISA for detection of antibodies against Mycobacterium avium subspecies paratuberculosis in individual milk and bulk milk samples of dairy herds. Vet. Microbiol. $125(1-2), 49-58$. 